\title{
METRNL reduced inflammation in sepsis-induced renal injury via PPAR $\delta$-dependent pathways
}

\author{
Jin $\mathrm{HU}^{1}$, Aiting $\mathrm{HE}^{2}$, Xiaolin $\mathrm{YUE}^{2}$, Minmin $\mathrm{ZHOU}^{2}$, Yanhong $\mathrm{ZHOU}^{3 *}$ (D)
}

\begin{abstract}
Sepsis is a systemic inflammatory response syndrome (SIRS) caused by infection, with complicated pathological mechanism and extremely high prevalence and fatality rate. In this study, we investigated the role of METRNL in sepsis-induced renal injury and to identify potential downstream molecules. Male C57BL/6 mice were subjected to laparotomy followed by extracorporeal cecum mobilization and ligation as vivo model. THP-1 cells were stimulated with LPS as vitro model. As compared to the normal tissue or normal serum samples, the tissue and serum of METRNL expression levels in sepsis-induced renal injury were reduced. METRNL protein reduced inflammation and inhibited renal injury in sepsis mice model. METRNL up-regulation inhibited inflammation in vitro model. The inhibition of METRNL promoted inflammation and renal injury in sepsis mice model. METRNL reduced inflammation in sepsis-induced renal injury via PPAR $\delta$-dependent pathways. In conclusion, we are the first to identify METRNL as a co-activator of PPAR $\delta$ to inhibit inflammation in sepsis-induced renal injury and potentiate the activity target of renal injury.
\end{abstract}

Keywords: METRNL; PPAR $\delta$; sepsis; renal injury; inflammation.

Practical Application: METRNL, a co-activator of PPAR $\boldsymbol{\delta}$, can be used to inhibit sepsis-induced kidney injury and inflammation, and help to further study the treatment strategies of inflammatory diseases.

\section{Introduction}

Sepsis is a systemic inflammatory response syndrome (SIRS) caused by infection, with complicated pathological mechanism and extremely high prevalence and fatality rate (Nadeem et al., 2021; Ma et al., 2019). Sepsis is easy to develop into septic shock and multiple organ dysfunction syndrome (MODS), which is life-threatening (Nadeem et al., 2021; Ma et al., 2019). Acute kidney injury (AKI) pathologically characterized by progressively declined renal function is a common complication of sepsis (Wang et al., 2021). Epidemiological studies have shown that approximately $40 \%$ of patients with sepsis will develop AKI (Yoo et al., 2020). Compared with common AKI, patients with sepsis-induced AKI have a worse prognosis, with a survival rate of only $70 \%$ (Ferrè et al., 2019). In addition, chronic kidney damage remains in survivors, severely affecting human health and quality of life (Liu et al., 2020). A lack of effective prognostic evaluation indicators is one of the main causes for the high mortality rate of AKI (Liu et al., 2020).

Peroxisome proliferator-activated receptor- $\beta$ (PPAR- $\beta$ ), also known as PPAR- $\delta$, is one of the members of the PPAR subgroup in the nuclear receptor superfamily (Gui et al., 2019). PPAR- $\beta$ may be vitally involved in inflammation, oxidative stress and apoptosis regulation (Kaur et al., 2021). By studying the three phenotypes of PPARs receptors, it has been found that the application of selective PPAR- $\beta$ agonists in vivo in subclinical studies could exert an anti-inflammatory impact, thereby playing a protective role in inflammatory diseases (Badawy et al., 2019; Pu et al., 2020).
Meteorin-like (METRNL) is abundantly expressed in skeletal muscle and is a newly discovered muscle factor. Physiological factors such as exercise and temperature changes have been revealed to be involved in the regulation of METRNL expression (Miao et al., 2020). In adipose tissue, METRNL activates M2 macrophages, induces increased heat production, and promotes energy consumption (Sobieh et al., 2021). In addition, METRNL also plays an important biological role in the processes of bone formation, adipocyte differentiation and proliferation, and immune response (Yao et al., 2021). The expression of METRNL changes significantly in the occurrence and development of obesity, type II diabetes and skin diseases, and is also involved in the pathophysiological regulation (Aleassa, 2020). In this study, we investigated the role of METRNL in sepsis-induced renal injury and to identify potential downstream molecules.

\section{Materials and methods}

\subsection{Arthritis model studies}

Eight-week-old male C57BL/6 mice were housed separately under controlled temperature $\left(22 \pm 3{ }^{\circ} \mathrm{C}\right), 50 \pm 20 \%$ humidity, light-dark cycle of $12 \mathrm{~h}$ and free access to food and water. According to the principles of the Declaration of Helsinki, this experiment was approved by Chongqing University Cancer 
Hospital. Male C57BL/6 mice were anesthetized using $50 \mathrm{mg} / \mathrm{kg}$ pentobarbital sodium and then subjected to laparotomy followed by extracorporeal cecum mobilization and ligation.

\subsection{Microarray experiments and quantitative RT-PCR}

Microarray experiments were performed at the Genminix Informatics (China). Gene expression profiles were analyzed with the Human Exon 1.0 ST GeneChip (Affymetrix).

The TRIzol kit (Invitrogen, Carlsbad, CA, USA) was used to extract the total RNA and reversely transcribed into complementary Deoxyribose Nucleic Acid (cDNA) using Reverse Transcription Kit (TaKaRa Bio Inc., Kusatsu, Japan). Real-time PCR was performed on a Bio-Rad Real-Time PCR System (Applied Biosystems Co., Foster City, US). The PCR cycle was performed as follows: stage 1,1 cycle at $95^{\circ} \mathrm{C}$ for $30 \mathrm{~s}$; stage 2 , 40 cycles at $95{ }^{\circ} \mathrm{C}$ for $5 \mathrm{~s}$ and, $60^{\circ} \mathrm{C}$ for $30 \mathrm{~s}$. The level of gene expression was normalized to $\beta$-Actin.

\subsection{Inflammatory factors by ELISA assay}

Cell supernatant, cell samples, serum and tissue samples were collected and then the concentrations of TNF- $\alpha$, IL-4, IL-6, IL-1 $\beta$ and IL-10 levels were measured using ELISA kits.

\subsection{Cell culture and vitro model}

THP- 1 cells were cultured in 1640- modified Eagle medium (Gibco, Grand Island, NY, United States), with 10\% fetal bovine serum (FBS, Gibco), in a humidified $5 \% \mathrm{CO} 2$ incubator at $37^{\circ} \mathrm{C}$. THP- 1 cells were performed transfections using Lipofectamine 2000 (Thermo Fisher Scientific). METRNL plasmids $(0.4 \mu \mathrm{g} / \mathrm{mL})$ or METRNL siRNAs $(20 \mathrm{nmol} / \mathrm{mL})$ and negative $(20 \mathrm{nmol} / \mathrm{mL})$ were transfected in the serum-free and antibioticfree media. After $48 \mathrm{~h}$ of transfection, THP-1 cells were stimulated with LPS (200 ng/mL, Sigma-Aldrich) for $4 \mathrm{~h}$.

\subsection{Immunofluorescence}

After $48 \mathrm{~h}$ of transfection, cells samples were fixed with $4 \%$ paraformaldehyde for $24 \mathrm{~h}$ at room temperature and stained with Triton X-100. Cells samples were determined by immunofluorescence staining using anti-METRNL antibody (1:100, Cell Signaling Technology, US) and PPAR $\delta$ (1:100, Cell Signaling Technology, US) overnight at $4{ }^{\circ} \mathrm{C}$ after blocked with $5 \%$ BSA for $1 \mathrm{~h}$. Alex 480 conjugated secondary antibody (1:100, Thermo Fisher) or Alex 555 conjugated secondary antibody (1:100, Thermo Fisher) was used to obtain fluorescence images (LSM 510 Meta; Carl Zeiss) after DAPI staining.

\subsection{Western blot assay}

Cells and tissue samples were lysed for protein extraction using RIPA assay. The concentration of each protein sample was determined by a BCA (bicinchoninic acid) kit. Equal amounts of protein were separated by $10 \%$ sodium dodecyl sulfate-polyacrylamide gel electrophoresis and transferred to a polyvinylidene fluoride membrane (Bio-Rad, Hercules, CA, United States). Membranes were blocked using 5\% non-fat dry milk with TBST buffer for
$1 \mathrm{~h}$, then incubated overnight at $4^{\circ} \mathrm{C}$ with METRNL (1:1000, Cell Signaling Technology, US), PPAR $\delta$ (1:100, Cell Signaling Technology, US) and $\beta$-Actin (1:5000, Bioworld Technology, Inc.). After washing, membranes were probed further with horseradish peroxidase-conjugated goat anti-rabbit (1:5000, Gibco, Rockville, MD, USA). After washing with TBST for $15 \mathrm{~min}$, membranes were exposed by enhanced chemiluminescence method (Thermo Fisher Scientific, Waltham, MA, USA).

\subsection{Data analysis}

The quantitative data were represented as mean \pm standard deviation $(\overline{\mathrm{x}} \pm \mathrm{s})$. Statistical analyses were performed using GraphPad Prism 5 software. P values $<0.05$ were taken to indicate statistical significance. ANOVA followed by Dunnett's test was used to compare three and more groups.

\section{Results}

\subsection{The tissue and serum of METRNL expression levels in sepsis-induced renal injury}

To verify the mechanism of anti-inflammation in sepsis-induced renal injury, we analyzed that the changes of anti-inflammation gene in sepsis-induced renal injury using microarray analysis. METRNL gene expression was reduced in mice of sepsis-induced renal injury (Figure 1A). As compared to the normal tissue or normal serum samples, the tissue and serum of METRNL expression levels in sepsis-induced renal injury were reduced (Figure 1B-D).

\subsection{METRNL protein reduced inflammation and inhibited renal injury in sepsis mice model}

To observe the function of METRNL on inflammation in sepsis-induced renal injury, we used reorganized METRNL protein to inject into mice with sepsis. Reorganized METRNL protein increased body weight, reduced kidney weight/body weight, $\mathrm{Cr}$ and BUN levels, suppressed TNF- $\alpha$, IL-1 $\beta$, IL- 6 and IL-4 levels, and promoted IL-10 levels in serum and kidney tissue of sepsis mice model (Figure 2).

\subsection{The inhibition of METRNL promoted inflammation and renal injury in sepsis mice model}

To further observe the function of METRNL on inflammation in sepsis-induced renal injury, we used anti-METRNL body into mice with sepsis. Anti-METRNL body decreased body weight, increased kidney weight/body weight, $\mathrm{Cr}$ and BUN levels, and promoted TNF- $\alpha$, IL-1 $\beta$, IL- 6 and IL- 4 levels in serum and kidney tissue of sepsis mice model (Figure 3).

\subsection{METRNL up-regulation inhibited inflammation in vitro model}

In order to verify the effects of METRNL on inflammation in vitro model, METRNL plasmid induced METRNL expression, reduced TNF- $\alpha$, IL-1 $\beta$, IL- 6 and IL-4 levels, and increased IL10 levels in vitro model of sepsis (Figure 4A-F). Si-METRNL mimics reduced METRNL expression, induced TNF- $\alpha$, IL-1 $\beta$, 


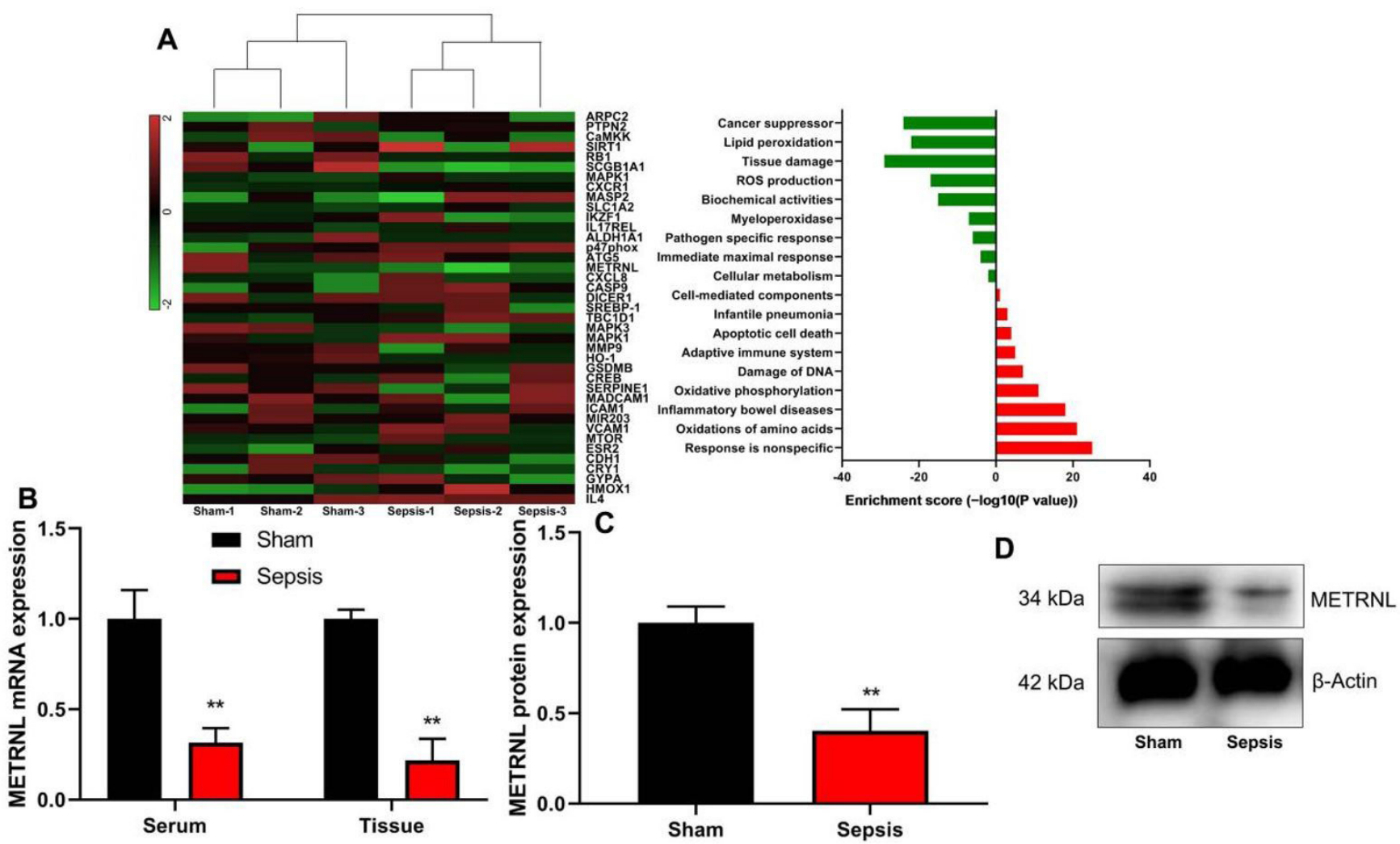

Figure 1. The tissue and serum of METRNL expression levels in sepsis-induced renal injury. Heat map and microarray data (A), METRNL mRNA (B) and protein (C, D) expressions, NLRX1 expression by immunohistochemical (E) and immunofluorescence (F). Sham, sham control group; Sepsis, sepsis model group. \#\# $<0.01$ compared with sham control group.
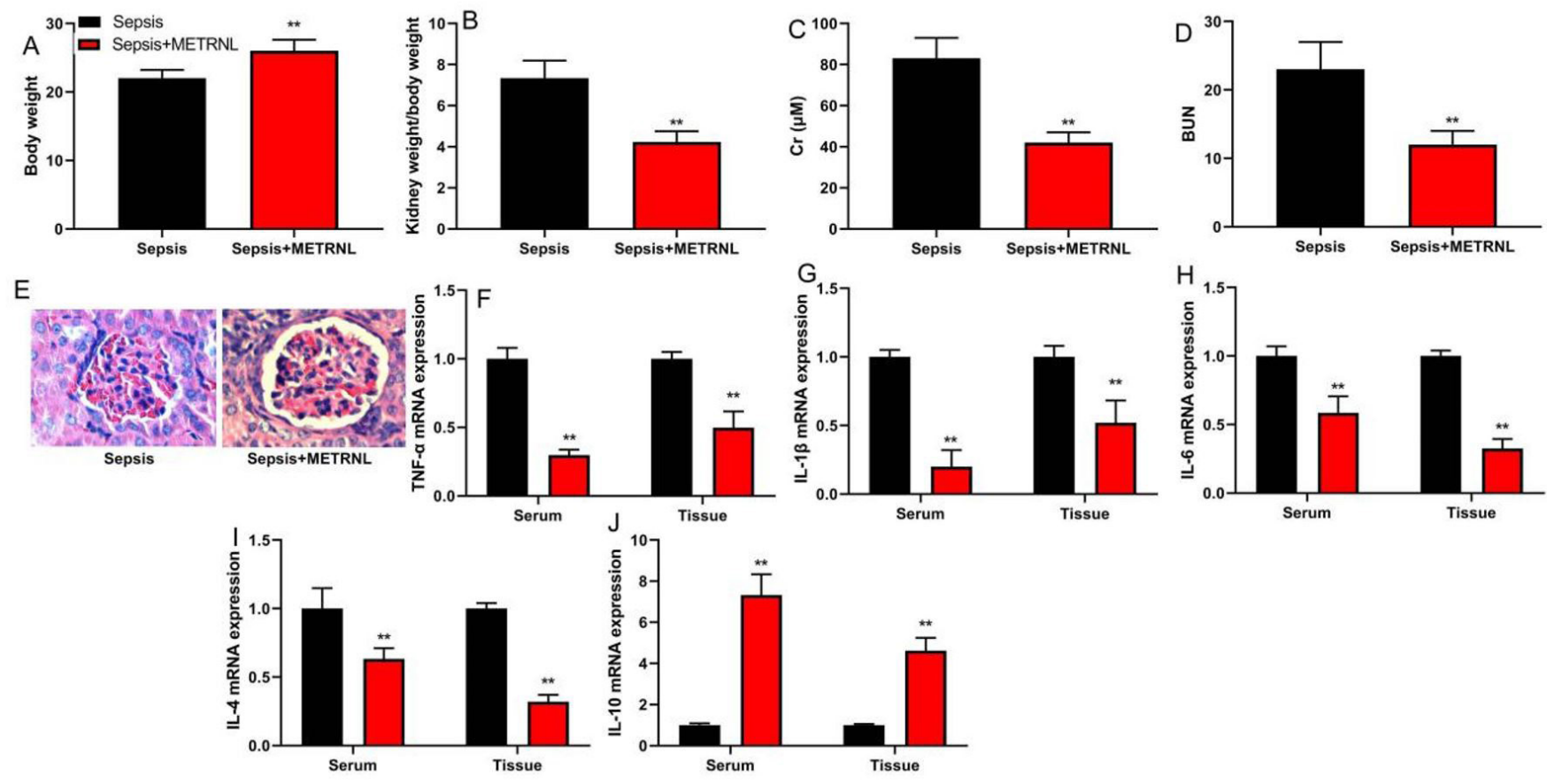

Figure 2. METRNL protein reduced inflammation and inhibited renal injury in sepsis mice model. Body weight (A), kidney weight/body weight (B), Cr levels (C), BUN levels (D), glomerulus (HE, E), TNF- $\alpha$ (F), IL-1 $\beta$ (G), IL-6 (H), IL-4 (I) and IL-10 (J) levels in serum and tissue of mice with renal injury. Sepsis, sepsis model group; Sepsis+METRNL, sepsis model by human METRNL protein group. \#\#p <0.01 compared with sham control group. 

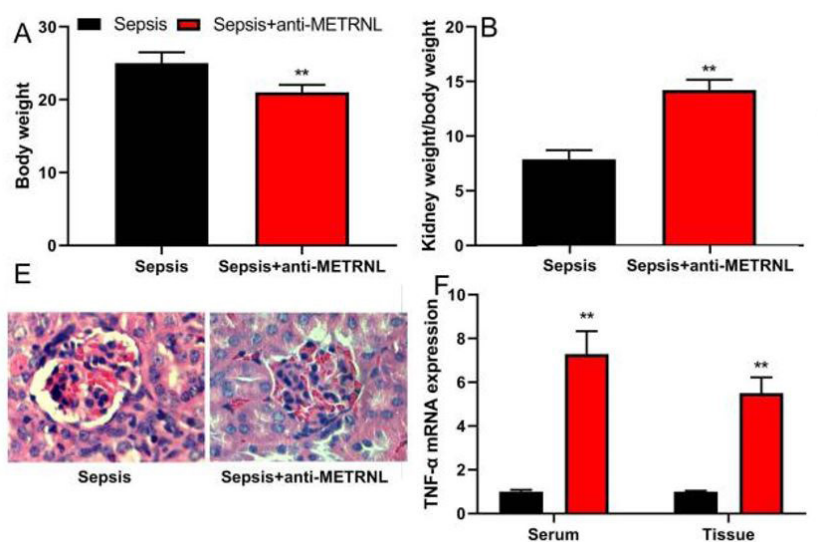
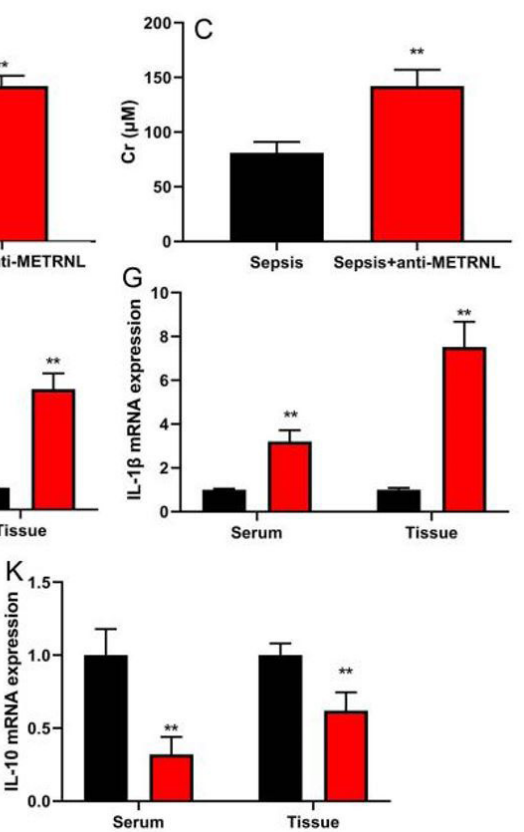
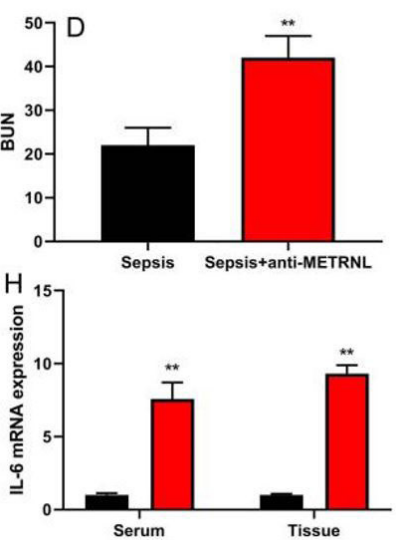

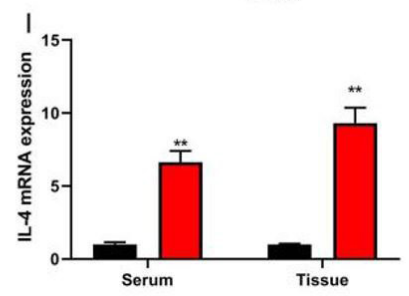

Figure 3. The inhibition of METRNL promoted inflammation and renal injury in sepsis mice model. Body weight (A), kidney weight/body weight (B), Cr levels (C), BUN levels (D), glomerulus (HE, E), TNF- $\alpha$ (F), IL-1 1 (G), IL-6 (H), IL-4 (I) and IL-10 (J) levels in serum and tissue of mice with renal injury. Sepsis, sepsis model group; Sepsis+anti-METRNL, sepsis model by anti-METRNL body group. \#\#p < 0.01 compared with sham control group.
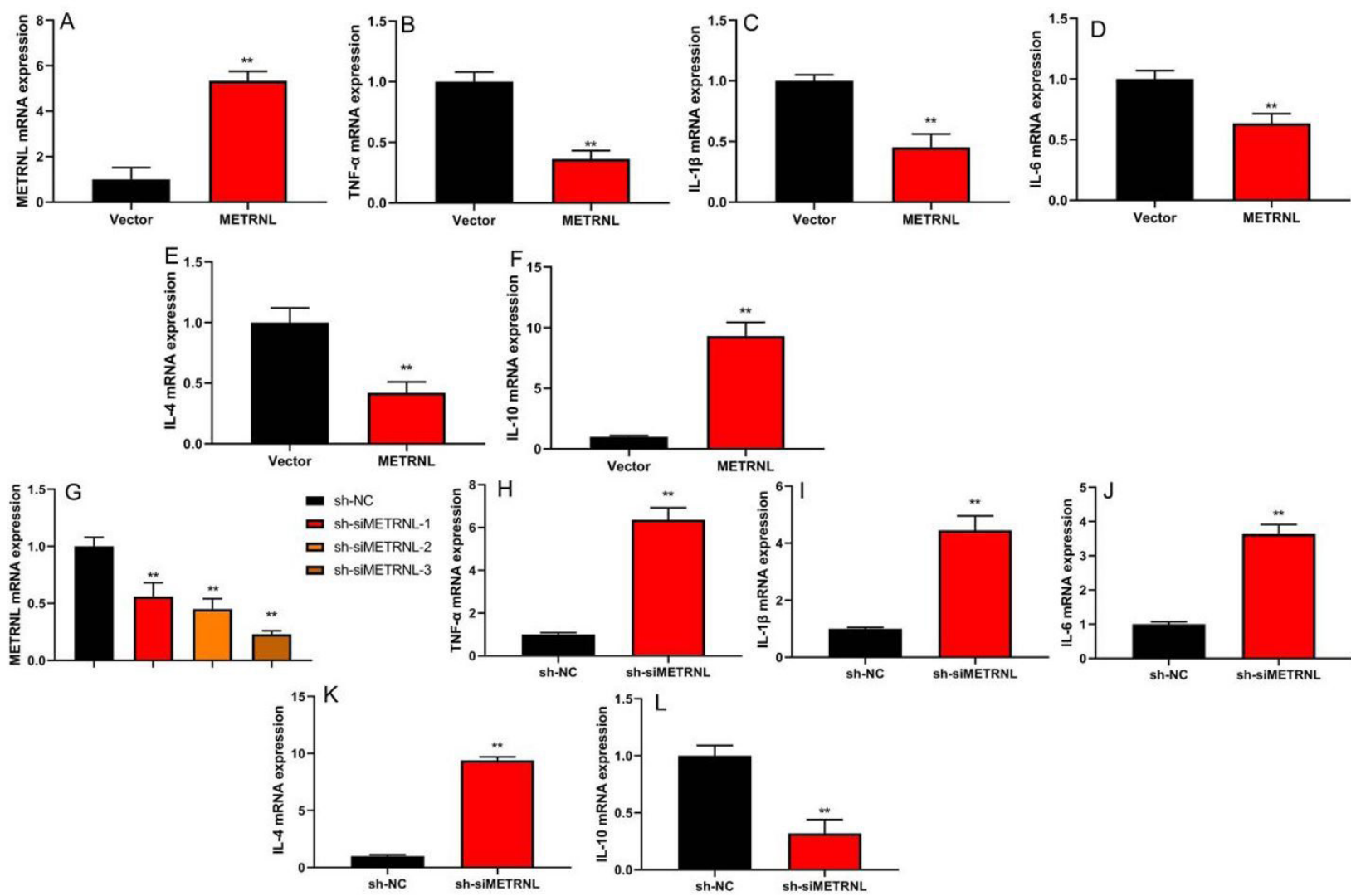

Figure 4. METRNL up-regulation inhibited inflammation in vitro model. METRNL expression (A), TNF- $\alpha$ (B), IL-1 $\beta$ (C), IL-6 (D), IL-4 (E) and IL-10 (F) levels in vitro model of METRNL over-expression; METRNL expression (G), TNF- $\alpha$ (H), IL-1 $\beta$ (I), IL-6 (J), IL-4 (K) and IL-10 (L) levels in vitro model of METRNL down-regulation. Vector, Vector control; METRNL, over-expression of METRNL; sh-NC, sh-negative control group; sh-siMETRNL-1; down-regulation METRNL-1 group; sh-siMETRNL-2; down-regulation METRNL-2 group; sh-siMETRNL-3; down-regulation METRNL-3 group; sh-siMETRNL; down-regulation METRNL group. ${ }^{* *} \mathrm{p}<0.01$ compared with vector control or sh-negative control group. 
IL-6 and IL-4 levels, and suppressed IL-10 levels in vitro model of sepsis (Figure 4G-L).

\subsection{METRNL reduced inflammation in sepsis-induced renal injury via PPARS-dependent pathways}

The experiment investigated the mechanism linking METRNL to anti-inflammatory cytokine production. Microarray analysis showed that PPAR $\delta$ is an target spot for the anti-inflammation effects of METRNL in sepsis-induced renal injury (Figure 5A).
METRNL over-expression induced METRNL and PPAR $\delta$ protein expressions in vitro model (Figure 5B-D). Down-regulation of METRNL suppressed METRNL and PPAR $\delta$ protein expressions in vitro model (Figure 5E, F). Over-expression of METRNL induced METRNL and PPAR $\delta$ protein expressions in vitro model (Figure 5G). Reorganized METRNL protein induced PPAR $\delta$ protein expression in mice of sepsis-induced renal injury (Figure 5H, I). Anti-METRNL body suppressed PPAR $\delta$ protein expression in mice of sepsis-induced renal injury (Figure 5J, K).


Figure 5. METRNL reduced inflammation in sepsis-induced renal injury via PPAR $\delta$-dependent pathways. Heat map and refine results of gene chip (A), METRNL and PPAR $\delta$ protein expressions in vitro model by over-expression of METRNL (B, C, D), METRNL and PPAR $\delta$ protein expressions in vitro model by over-expression of METRNL (E, F, G), Immunofluorescence for METRNL and PPAR $\delta$ protein expressions in vitro model by over-expression of METRNL (H), PPAR $\delta$ protein expressions in mice with sepsis-induced renal injury by human METRNL protein (H and I), PPAR $\delta$ protein expressions in mice with sepsis-induced renal injury by anti-METRNL body (J and K). Vector, Vector control; METRNL, over-expression of METRNL; sh-NC, sh-negative control group; sh-siMETRNL; down-regulation METRNL group; Sepsis, sepsis model group; Sepsis+METRNL, sepsis model by human METRNL protein group; Sepsis+anti-METRNL, sepsis model by anti-METRNL body group. ${ }^{* *} \mathrm{p}<0.01$ compared with vector control or sh-negative control group or sham control group. 


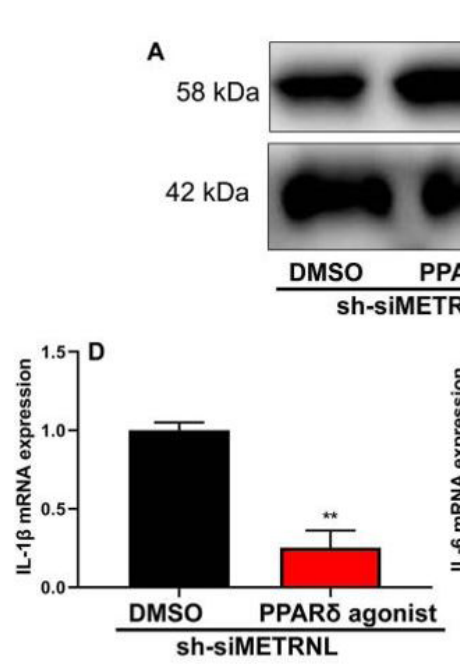

H

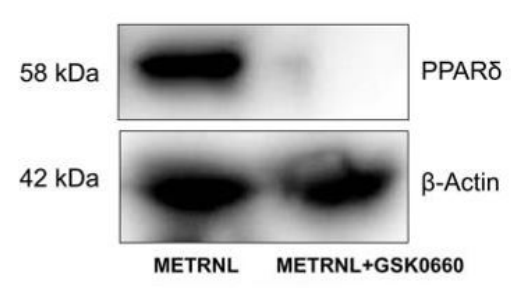

PPARס

$\beta$-Actin

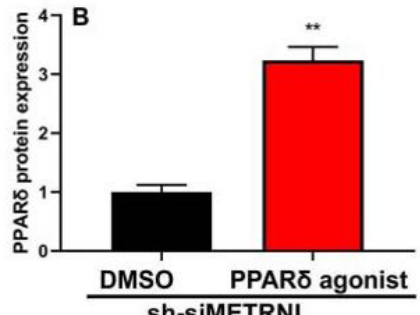

Sh-SIMETRNL

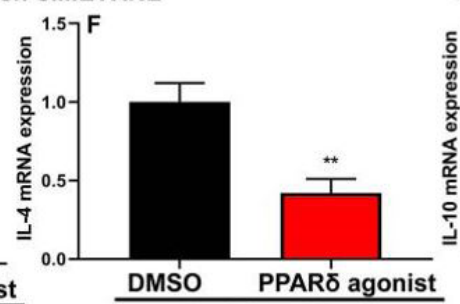

sh-SIMETRNL
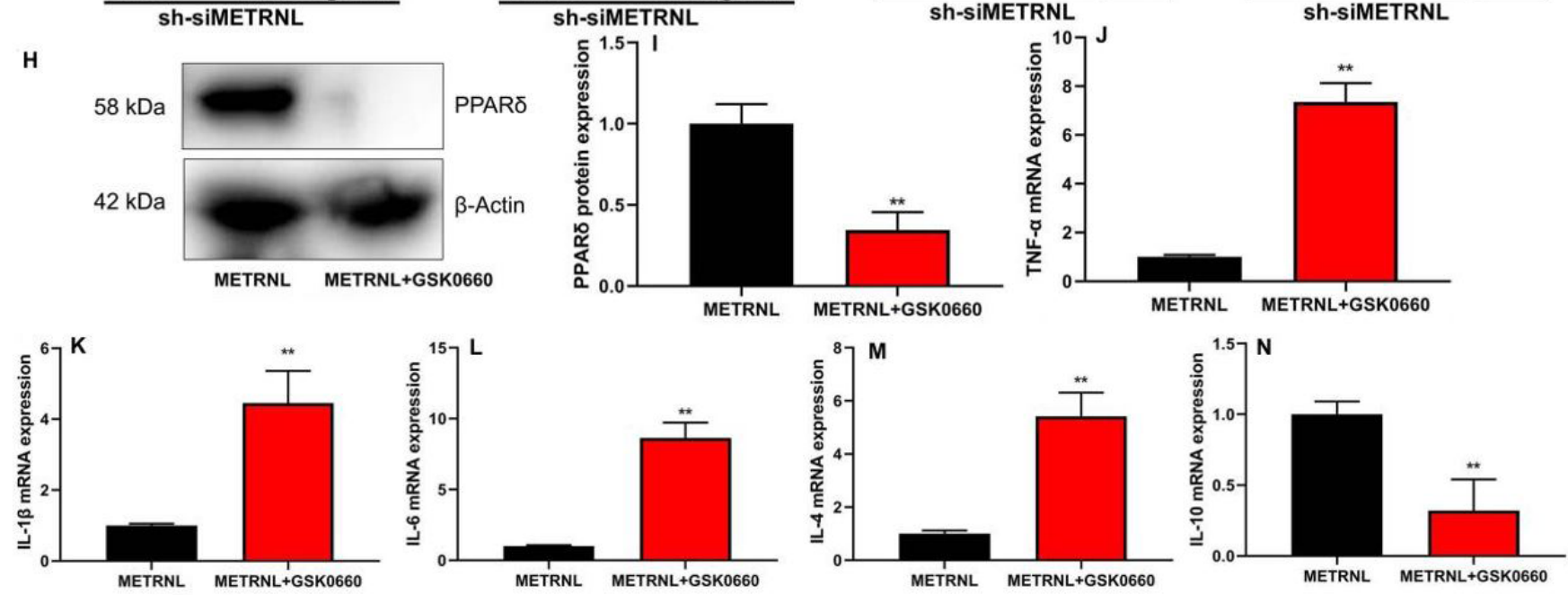

Figure 6. PPAR $\delta$ is target spot for the anti-inflammation effects of METRNL in sepsis-induced renal injury. PPAR $\delta$ protein expression (A and B), TNF- $\alpha(C)$, IL-1 $\beta$ (D), IL-6 (E), IL-4 (F) and IL-10 (G) levels in vitro model of METRNL down-regulation and PPAR $\delta$ agonist; PPAR $\delta$ protein expression (A, B), TNF- $\alpha$ (C), IL-1 $\beta$ (D), IL-6 (E), IL-4 (F) and IL-10 (G) levels in vitro model of METRNL over-expression and PPAR $\delta$ inhibitor. DMSO+sh-si-METRNL, down-regulation of METRNL group; PPAR $\delta$ agonist+sh-si-METRNL, METRNL down-regulation and PPAR $\delta$ agonist; METRNL, METRNL over-expression; METRNL+GSK0660, METRNL over-expression+GSK0660. ${ }^{* *}$ p $<0.01$ compared with DMSO+sh-siMETRNL or METRNL over-expression group.

\subsection{PPAR $\delta$ is target spot for the anti-inflammation effects of METRNL in sepsis-induced renal injury}

PPAR $\delta$ agonist (4 nM, L-165041) induced PPAR $\delta$ protein expression, inhibited TNF- $\alpha$, IL-1 $\beta$, IL- 6 and IL- 4 levels, and increased IL-10 levels in vitro model of sepsis (Figure 6A-G). PPAR $\delta$ inhibitor ( $3 \mathrm{nM}$, GSK3787) suppressed PPAR $\delta$ protein expression, increased TNF- $\alpha$, IL-1 $\beta$, IL- 6 and IL- 4 levels, and decreased IL-10 levels in vitro model of sepsis (Figure 6H-N).

\section{Discussion}

There are few epidemiological studies of sepsis-caused AKI. Present studies have shown that its fatality rate is as high as $70 \%$, which is significantly higher than that of sepsis patients without organ damage (Wang et al., 2020). If timely and effective intervention can be implemented in the early stage of AKI in patients with sepsis, it is possible to reduce the mortality of patients with sepsis (Poudel et al., 2020). These results of this study support that the tissue and serum of METRNL expression levels in sepsis-induced renal injury were reduced. Ushach et al. showed that METRNL is a novel immunoregulatory cytokine associated with inflammatory responses (Ushach et al., 2018). These parameters indicate that METRNL maybe participated in sepsis-caused AKI.

AKI is an independent risk factor to predict death in patients with sepsis (Mulay et al., 2016). It is of great scientific significance to find key molecules that mediate the damage of renal tubular epithelial cells in sepsis-induced AKI and to elucidate its regulation mechanism for early intervention of sepsis-caused AKI (Keir \& Kellum, 2015). In recent years, studies have found that bacterial endotoxin and its inflammatory factors are the direct and important causes of renal injury (Alobaidi et al., 
2015). Interestingly, this study showed that METRNL reduced inflammation and inhibited renal injury in vivo or vitro model of sepsis-caused AKI. Kerget et al. showed that Metrnl is a adipokine involved in the anti-inflammation effects to acute exacerbations of chronic obstructive pulmonary disease (Kerget et al., 2020). These results demonstrate that METRNL exacerbates antiinflammatory response of sepsis-caused AKI.

PPARs are expressed in dendritic cells, macrophages, B and $\mathrm{T}$ lymphocytes. In addition, PPARs are also expressed in epithelial cells, playing an important role in the mucosal immune response (Parikh, 2019). When activated by endogenous or synthetic ligands, PPARs can down-regulate various components of inflammatory responses, such as cytokines and chemotaxis (Parikh, 2019; Pu et al., 2019). PPAR-C and its ligands have important anti-inflammatory effects (Libby et al., 2021). PPAR $\delta$ ligand can inhibit the expression of IL- 6 and IL-1B in monocytes, and can also inhibit the expression of inducible NOS, MMP9 and type A scavenger receptors in macrophages. In our in experiment, we found that METRNL reduced inflammation in sepsis-induced renal injury via PPAR $\delta$-dependent pathways. Jung et al. METRNL attenuates lipid-induced inflammation PPAR $\delta$-dependent pathways in skeletal muscle of mice (Jung et al., 2018). It is implied that METRNL is a key molecule involved in the anti-inflammation effects of sepsis-induced renal injury by $\operatorname{PPAR} \delta$-dependent pathways.

In conclusion, we are the first to identify METRNL as an inactivator of NF- $\kappa \mathrm{B}$ p 65 to reduce inflammation of sepsis-induced renal injury by PPAR $\delta$-dependent pathways, which prevented inflammation of sepsis-induced renal injury and maintained more anti-inflammation effects. Our findings shed light on the therapeutic strategies of inflammatory diseases.

\section{References}

Aleassa, E. M. (2020). Comment on: effect of sleeve gastrectomy on the expression of Meteorin-like (METRNL) and irisin (FNDC5) in muscle and brown adipose tissue and its impact on (UCPs) in diet-induced obesity rats. Surgery for Obesity and Related Diseases, 16(12), 1918-1919. http://dx.doi.org/10.1016/j.soard.2020.08.027. PMid:33032915.

Alobaidi, R., Basu, R. K., Goldstein, S. L., \& Bagshaw, S. M. (2015). Sepsis-associated acute kidney injury. Seminars in Nephrology, 35(1), 2-11. http://dx.doi.org/10.1016/j.semnephrol.2015.01.002. PMid:25795495.

Badawy, A. M., El-Naga, R. N., Gad, A. M., Tadros, M. G., \& Fawzy, H. M. (2019). Wogonin pre-treatment attenuates cisplatin-induced nephrotoxicity in rats: impact on PPAR- $\gamma$, inflammation, apoptosis and Wnt/ $\beta$-catenin pathway. Chemico-Biological Interactions, 308, 137-146. http://dx.doi.org/10.1016/j.cbi.2019.05.029. PMid:31103702.

Ferrè, S., Deng, Y., Huen, S. C., Lu, C. Y., Scherer, P. E., Igarashi, P., \& Moe, O. W. (2019). Renal tubular cell spliced X-box binding protein 1 (Xbp1s) has a unique role in sepsis-induced acute kidney injury and inflammation. Kidney International, 96(6), 1359-1373. http:// dx.doi.org/10.1016/j.kint.2019.06.023. PMid:31601454.

Gui, Y., Lu, Q., Gu, M., Wang, M., Liang, Y., Zhu, X., Xue, X., Sun, X., He, W., Yang, J., Zhao, A. Z., Xiao, B., \& Dai, C. (2019). Fibroblast mTOR/PPAR $\gamma / \mathrm{HGF}$ axis protects against tubular cell death and acute kidney injury. Cell Death and Differentiation, 26(12), 27742789. http://dx.doi.org/10.1038/s41418-019-0336-3. PMid:31024074.
Jung, T. W., Lee, S. H., Kim, H. C., Bang, J. S., El-Aty, A. M. A., Hacımüftüoğlu, A., Shin, Y. K., \& Jeong, J. H. (2018). METRNL attenuates lipid-induced inflammation and insulin resistance via AMPK or PPAR $\delta$-dependent pathways in skeletal muscle of mice. Experimental \& Molecular Medicine, 50(9), 1-11. http://dx.doi. org/10.1038/s12276-018-0147-5.

Kaur, T., Singh, D., \& Singh, A. P. (2021). Stevioside protects against rhabdomyolysis-induced acute kidney injury through PPAR- $\gamma$ agonism in rats. Drug Development Research, 82(1), 59-67. PMid:32737941.

Keir, I., \& Kellum, J. A. (2015). Acute kidney injury in severe sepsis: pathophysiology, diagnosis, and treatment recommendations. Journal of Veterinary Emergency and Critical Care, 25(2), 200-209. http:// dx.doi.org/10.1111/vec.12297. PMid:25845505.

Kerget, B., Afşin, D. E., Kerget, F., Aşkın, S., \& Akgün, M. (2020). Is Metrnl an adipokine involved in the anti-inflammatory response to acute exacerbations of COPD? Lung, 198(2), 307-314. http://dx.doi. org/10.1007/s00408-020-00327-4. PMid:31960164.

Libby, A. E., Jones, B., Lopez-Santiago, I., Rowland, E., \& Levi, M. (2021). Nuclear receptors in the kidney during health and disease. Molecular Aspects of Medicine, 78, 100935. http://dx.doi.org/10.1016/j. mam.2020.100935. PMid:33272705.

Liu, Z., Yang, D., Gao, J., Xiang, X., Hu, X., Li, S., Wu, W., Cai, J., Tang, C., Zhang, D., \& Dong, Z. (2020). Discovery and validation of miR-452 as an effective biomarker for acute kidney injury in sepsis. Theranostics, 10(26), 11963-11975. http://dx.doi.org/10.7150/ thno.50093. PMid:33204323.

Ma, S., Evans, R. G., Iguchi, N., Tare, M., Parkington, H. C., Bellomo, R., May, C. N., \& Lankadeva, Y. R. (2019). Sepsis-induced acute kidney injury: a disease of the microcirculation. Microcirculation, 26(2), e12483. http://dx.doi.org/10.1111/micc.12483. PMid:29908046.

Miao, Z. W., Hu, W. J., Li, Z. Y., \& Miao, C. Y. (2020). Involvement of the secreted protein Metrnl in human diseases. Acta Pharmacologica Sinica, 41(12), 1525-1530. http://dx.doi.org/10.1038/s41401-02000529-9. PMid:32999412.

Mulay, S. R., Holderied, A., Kumar, S. V., \& Anders, H. J. (2016). Targeting inflammation in so-called acute kidney injury. Seminars in Nephrology, 36(1), 17-30. http://dx.doi.org/10.1016/j.semnephrol.2016.01.006. PMid:27085732.

Nadeem, A., Ahmad, S. F., Al-Harbi, N. O., Ibrahim, K. E., Alqahtani, F., Alanazi, W. A., Mahmood, H. M., Alsanea, S., \& Attia, S. M. (2021). Bruton's tyrosine kinase inhibition attenuates oxidative stress in systemic immune cells and renal compartment during sepsis-induced acute kidney injury in mice. International Immunopharmacology, 90, 107123. http://dx.doi.org/10.1016/j.intimp.2020.107123. PMid:33168411.

Parikh, S. M. (2019). Metabolic stress resistance in acute kidney injury: evidence for a PPAR-gamma-coactivator-1 alpha-nicotinamide adenine dinucleotide pathway. Nephron, 143(3), 184-187. http:// dx.doi.org/10.1159/000500168. PMid:31055583.

Poudel, N., Zheng, S., Schinderle, C. M., Sun, N., Hu, S., \& Okusa, M. D. (2020). Peritubular capillary oxygen consumption in sepsis-induced AKI: multi-parametric photoacoustic microscopy. Nephron, 144(12), 621-625. http://dx.doi.org/10.1159/000511167. PMid:33147592.

Pu, Z., Che, Y., Zhang, W., Sun, H., Meng, T., Xie, H., Cao, L., \& Hao, H. (2019). Dual roles of IL-18 in colitis through regulation of the function and quantity of goblet cells. International Journal of Molecular Medicine, 43(6), 2291-2302. http://dx.doi.org/10.3892/ ijmm.2019.4156. PMid:31017261.

Pu, Z., Liu, Y., Li, C., Xu, M., Xie, H., \& Zhao, J. (2020). Using network pharmacology for systematic understanding of geniposide in ameliorating inflammatory responses in colitis through suppression 
of NLRP3 inflammasome in macrophage by AMPK/Sirt1 dependent signaling. The American Journal of Chinese Medicine, 48(7), 1693-1713. http://dx.doi.org/10.1142/S0192415X20500846. PMid:33202149.

Sobieh, B. H., Kassem, D. H., Zakaria, Z. M., \& El-Mesallamy, H. O. (2021). Potential emerging roles of the novel adipokines adipolin/ CTRP12 and meteorin-like/METRNL in obesity-osteoarthritis interplay. Cytokine, 138, 155368. http://dx.doi.org/10.1016/j. cyto.2020.155368. PMid:33248913.

Ushach, I., Arrevillaga-Boni, G., Heller, G. N., Pone, E., Hernandez-Ruiz, M., Catalan-Dibene, J., Hevezi, P., \& Zlotnik, A. (2018). Meteorinlike/meteorin- $\beta$ is a novel immunoregulatory cytokine associated with inflammation. Journal of Immunology, 201(12), 3669-3676. http://dx.doi.org/10.4049/jimmunol.1800435. PMid:30464051.

Wang, Y., Zhu, J., Liu, Z., Shu, S., Fu, Y., Liu, Y., Cai, J., Tang, C., Liu, Y., Yin, X., \& Dong, Z. (2021). The PINK1/PARK2/optineurin pathway of mitophagy is activated for protection in septic acute kidney injury. Redox Biology, 38, 101767. http://dx.doi.org/10.1016/j. redox.2020.101767. PMid:33137712.

Wang, Z., Wu, J., Hu, Z., Luo, C., Wang, P., Zhang, Y., \& Li, H. (2020). Dexmedetomidine alleviates lipopolysaccharide-induced acute kidney injury by inhibiting p75NTR-mediated oxidative stress and apoptosis. Oxidative Medicine and Cellular Longevity, 2020, 5454210. http://dx.doi.org/10.1155/2020/5454210. PMid:33194004.

Yao, Z., Lin, P., Wang, C., Wang, K., \& Sun, Y. (2021). Administration of metrnl delays the onset of diabetes in non-obese diabetic mice. Endocrine Journal, 68(2), 179-188. PMid:33162409.

Yoo, J. Y., Cha, D. R., Kim, B., An, E. J., Lee, S. R., Cha, J. J., Kang, Y. S., Ghee, J. Y., Han, J. Y., \& Bae, Y. S. (2020). LPS-induced acute kidney injury is mediated by nox4-SH3YL1. Cell Reports, 33(3), 108245. http://dx.doi.org/10.1016/j.celrep.2020.108245. PMid:33086058. 